\title{
War-affected children and psycho-social rehabilitation
}

\author{
Kumari Thoradeniya* \\ Department of Sociology, Faculty of Arts, University of Peradeniya, Peradeniya, Sri Lanka.
}

\begin{abstract}
The purpose of this paper is to examine how the concept of psycho-social and psycho-social programmes emerged and evolved. Further, this paper expects to identify the basic elements in a psycho-social rehabilitation programme, by using global level discourse regarding the effects of war on children and how they can be rehabilitated. According to literature, the impact of war on children was mainly given attention after Second World War and initially more attention was given on negative psychological effects. But later it was found that, due to war children faced another social risk as well and the different viewpoints which exemplified based on research findings on 'war-affected children' caused to restrategize psycho-social interventions. As a result, two main components were identified as important dimensions when conducting a psycho-social rehabilitation process in war context. First is the diagnosis of the impact of war on affected children. Second is analysis on 'social context', which refers to the immediate physical and social setting, including culture, religion, traditions, beliefs, people, structures and institutions. Finally, this study concludes that in order to heal war-affected children in a successful way three main components should be taken into account. As the first component the psycho-social rehabilitation programmes should ensure that they attend to the most vulnerable children who are in need of psycho-social care. The second component is resource adequacy and the third component is selection of suitable rehabilitation approaches and methods.
\end{abstract}

Keywords: War-affected children, psycho-social rehabilitation, healing.

\section{INTRODUCTION}

There is limited agreement among experts over the elements that need to be inherent in a psycho-social rehabilitation programme. However, a detailed study of the concept can reveal certain similarities and trends which help to draw conclusions over designing and developing such programmes. Therefore, the purpose of this paper is to examine how the concept of psycho-social and psycho-social programmes emerged and evolved.
Also this article aims to identify the basic elements in a psycho-social rehabilitation programme, by using global level discourse regarding the effects of war on children and how they can be rehabilitated. It also attempts to understand how these elements can have a successful impact on children.

According to previous research on war-affected children and psycho-social rehabilitation, two main factors should be taken into account when identifying the elements of a psycho-social rehabilitation programme. The first is identifying the need for psycho-social rehabilitation of war-affected children. Many researchers have highlighted that identifying harmful social and psychological factors and resolving them will be the first responsibility of a psycho-social rehabilitation programme. For instance, many researchers state that people can experience different kinds and levels of impact over the same particular events related to the war (Agger et al., 1995; Duncan and Arnston, 2004).

The second factor is identifying the importance of using social contextual features in rehabilitating waraffected children. Here, it is important to understand the needs and advancement of psycho-social rehabilitation in war contexts and comprehend the multi-dimensional nature of such rehabilitation. The advancements in psycho-social rehabilitation took on a notable change after the Second World War due to the medically and therapeutically-based approaches developed during this period. Further, advancement with research from the 1960 s to the 1970 s broadened the scope of psychosocial rehabilitation, which led to its multi-dimensional nature; the psychological, socio-cultural and economic dimensions, with each dimension influencing the others as well. Therefore, in order to plan a meaningful rehabilitation programme, the above two factors should be taken into account when attempting to successfully rehabilitate a person from the impact of war. 


\section{METHODOLOGY}

This paper provides a theoretical discussion regarding the psycho-social rehabilitation of war-affected children; it is solely based on a literature review on the relevant subject. However, two psycho-social rehabilitation programmes have been presented in this paper in order to identify the basic elements in a psycho-social rehabilitation programme and see how those programmes originated and what kind of impact they made on the war-affected children. In order to select these two psycho-social rehabilitation programmes, the author has examined a few studies on psycho-social rehabilitation programmes done in different war contexts and attempted to derive essential programmatic components needed for a successful programme. Even though there is a substantial literature on psycho-social rehabilitation programmes at a global level, the author's focus was on only two such programmes since these programmes provided valuable insight for the study. For an instance, these two programmes seem to use a multi-dimensional approach (psychological, socio-cultural and economic) for rehabilitating children, while priority is given to the needs of particular societies. At the same time, though they have their own way of rehabilitating children, the services of their community members are also utilised in tandem in suitable circumstances.

\section{NEED AND ADVANCEMENT OF PSYCHO- SOCIAL REHABILITATION IN WAR CONTEXTS}

Intense studies on the impact of war on children began after the Second World War (Loughry and Eyber, 2003). Most of these studies focused on recognising the 'psychological impact' of war (Tol et al., 2013). These researchers focused much attention on the effects of displacement since the Second World War, which caused many children to be displaced and separated from their families. For instance, citing Ressler et al.'s (1988) views, Loughry and Eyber (2003) have stated that within four days of the declaration of war in England, 750,000 school children were evacuated from their homes. The reason for the evacuation was fear for the death of parents, security and safety. However, they further state that evacuation and removal from their families caused the children severe mental trauma and agony.

Freud and Burlingham (1943) also did an important study on the impact of the war on children with special reference to the Second World War in Britain. Their research findings reveal that whenever some fundamentals are not present, the children are subject to lasting psychological malfunction. These are the need for personal attachment with parents and family members, emotional stability and permanency of educational influence. This study further reveals that severe trauma is caused to children who lose their parents and loved ones rather than seeing people killed, bombed or wounded in war. The study showed that mothers' and family members' love and care are decisive factors which stabilise children's mental status. In later years, Freud and Burlingham's idea of war-affected children was further confirmed by other researchers. For instance, Garbarino and Kostelny (1996) revealed that due to war, children are likely to lose family support - an essential in their development process - explaining the role of the family, especially of the mother in early childhood development. If parents die in a war situation or experience stress and exhibit traumatic symptoms, or are displaced, children experience growth stagnation, including psychological stagnation and under development.

However, after the Vietnam war, there seems to have been more systematic research done on the 'psychological effects' of the war on children. Especially after introducing the concept of Post-Traumatic Stress Disorder (PTSD) by the Diagnostic and Statistical Manual of Mental Disorders, third edition published in 1980 (Schnurr et al., 2002), most of the researchers seem to use this concept to examine the impact of war on individuals. PTSD surfaced as a result of studying mental conditions of returning soldiers from the Vietnam War and it dealt with circumstances such as nightmares, flashbacks and painful memories of events which resulted in a breaking down of the personal and social life of individuals (Figley, 1978). Thus it is apparent that through the development of concepts such as PTSD, trauma and stress within the mental health field, they have developed new frameworks to explain the impact of war, and even how to treat individuals.

However, from the 1960s to the 1970s, psychosocial rehabilitation changed its course with the approach turning from a medical and therapeutic base to social integration. As mentioned earlier, medication and psychotherapy were the two major treatment approaches, with little attention given to supporting and facilitating daily functioning and social interaction of war-affected children. Therapeutic interventions often had little impact on daily living, socialisation and work opportunities and there were often barriers to social inclusion in the form of stigma and prejudice (Pupavac, 2004; Summerfield, 1996; Cliffe et al., 2000; Monteiro, 2004). Therefore, psycho-social rehabilitation advanced with the aim of aiding the community integration and independence of individuals having mental health issues after much intense research during the late 1970s. 


\section{PSYCHO-SOCIAL REHABILITATION AS A MULTI-DIMENSIONAL CONCEPT}

\section{Psychological dimension}

After the Second World War, the psychological approaches of both bio-medical and counselling types were utilised to treat and rehabilitate children, upon the recommendation of mental health experts. The main focus was placed on 'risk factors' faced by children and their direct psychological impacts. With diagnosis and advancement of 'Post Traumatic Stress Disorder' (PTSD) in the late 1980s, many of the rehabilitation efforts coalesced around this condition. Many forms of psychotherapy have been advocated including basic counselling practices for the many treatment responses of PTSD, including education about the condition and provision of safety and support.

However, these kinds of psychological problems or 'risk factors' were mainly treated using modern mental health mechanisms under the Bio-Medical Approach. Bio-Medical Approach was termed differently by experts; Richman (1996) identifies it as 'Specialist Approach', while others named it as 'Curative Approach' (Duncan and Arntson, 2004; Kalksma, 2005). However, treatments such as psychotherapy (Cognitive therapy, Behaviour therapy, Group Therapy and Electro Convulsion Therapy) and psychopharmacology (drugs used in mental disorders) were popular methods under this approach, while different methods of counselling also became popular in the treatment of war-affected populations. All these treatments should, however, be handled only by well-trained professionals (Fazel and Stein, 2002; Kalksma, 2005). Especially after the Second World War, children's situations became so complicated that they needed to use these bio-medical and counselling methods to address their psychological issues. It was easily adopted in that context because many Second World War-affected countries were European nations and they possessed the necessary expertise to practice these advanced methods.

In the contemporary world though, most of the armed conflicts take place in developing nations where the mental health field is under developed, given that some of the psychological concepts and treatments have surfaced only recently even in the developed countries. Further, Duncan and Arnston (2004) claim that the number of individuals who require psychological treatment through bio-medical or advanced psychological therapy is likely to be minimal compared to the total number of people affected by wars. They classify the manner in which individuals, including children can be affected by war under three categories. They are: a) severely affected group b) at-risk group and c) generally affected group. According to Duncan and Arnston (2004), the 'severely affected' group is likely to be about 10 percent of the total population while the 'at-risk' group is likely to be about 20 percent and 'generally affected' group is about 70 percent. Therefore, the advanced psychological treatments are only needed for those 10 percent who are severely affected while the other 90 percent need solutions which are likely to be discovered within respective social and economic frameworks.

Further, Richman (1996) expresses that some of these advanced psychiatric and psychological methodologies are not suitable to be practiced when the population is large. This is because it is time consuming and costly to work with individuals for over a period of time; also that some of the tools like screening instruments or questionnaires which are used to measure stress levels or assess PTSD symptoms are not feasible, because in remote war contexts most people are illiterate and/or not familiar with the filling of questionnaires. Their levels of understanding might differ and the terminology used in the questionnaires might not be appropriate. Though such shortcomings exist in these psychiatric and psychological approaches, it is observed that they still can play a vital role in psycho-social rehabilitation.

\section{Socio-cultural dimension}

Race, tradition, language, social status, religious and cultural beliefs are important phenomena influencing an individual's life. These are diverse in nature and they intermingle with each other; a society is formed by these fundamentals. Therefore, the social context of an individual is of utmost importance to understand his/her behaviour and attitudes. According to the Social Context Theory of Earle and Earle (1999), social structure, social processes and social realities are characterised as the basic components of a social context. The social structure and institutions which influence behaviour include family, education, religion and politics. These social processes are the media through which people view and interact with social structures, while social realities are ideas or behaviours that all individuals within a given society recognise, even if they do not always accept or practice them. These cultural and social contextual elements define the socio-cultural dimension. People are bound and governed by socio-cultural elements which have a very strong influence on their physical and psychological conduct. Therefore, rehabilitation could likewise be culturally directed and diverse. 
The elements in the social context have a unique ability to heal people who have undergone traumatic experiences in life as suggested by the evidence based research of many researchers. One of the examples is the 'sense of coherence theory of stress' put forward by Antonovesky (1979) based on a research done in Israel. Though this study was not done specifically on children affected by war, it did analyse the protective factors that led to the coping strategies of individuals in a war situation. This study was done using a group of women who had undergone torture in a prison during the Second World War. According to the findings of Antonovesky (1979), although these women were tortured and had aged with time, they had commendably maintained mental and physical stability. Antonovesky mentions that despite the fact that they had undergone severe trauma while in the prison, after they returned to Israel, the social support and religious environment helped them to re-build themselves both mentally and physically. Thus he concludes with the following statement that social support can play a crucial role in maintaining the healthy physical and mental life of a person even after severe trauma.

\footnotetext{
"A strong sense of coherence on the one hand, is fostered by social supports and on the other hand, enables one to mobilize tangible appraisal and emotional support in coping with stressors" (Antonovesky, 1979:165).
}

Moskivitz (1983) also conducted important research on children's adaptation to war conditions. In her study, Moskivitz mainly examines the present life of children who have fled to Britain and were survivors of the Second World War. According to Moskivitz, these children were between ages of 3 to 11 years, with majority being the citizens of America and Israel. Moskivitz (1983) has interviewed 24 of these survivors attempting to examine how the childhood experience of war had influenced their adult life. Through the research findings she reveals that they continue to suffer the loss of everything they valued along with the feeling of being an outsider in a foreign land. However, she further reveals that despite the violent and fearful experiences they faced as children, they did not exhibit symptoms of serious mental disorders or unusual behaviours. As an example, the researcher confirms that most of them respect human values, possess high spirituality and exhibit feelings of active compassion towards other human beings. The researcher reveals that of the full group under study, one adult of 60 years got addicted to drugs and another spent life in a mental hospital, while all others led normal lives. Moskivitz found four significant protective factors that can be associated with this ability to lead normal lives after experiencing a traumatic period in childhood. These are:

1. The immense trust in religious beliefs.

2. The feeling of love and care shown by caregivers and society.

3. Identifying their parents.

4. Making children feel valued and allowing them to take up social responsibilities.

Moskivitz concludes that despite having to face numerous hardships in their childhood, through the support of social context, people can escape negative impact and reach normalcy.

The above research confirms the correlation between social contextual factors and abilities to cope with trauma, and how each factor influences the healing and rehabilitation process of individuals. Researchers further confirmed that 'family' is one of the strongest social contextual elements in helping war-affected children to overcome their war impacts. Research findings reveal that love, care and support received from mother and other family members are vital to cope with traumatic situations (Garbarino and Kostelny, 1996). Another important element is the peer group relationships. Boyden et al. (2005) say:

"positive peer relationships provide children with an area of support outside family, in which they can experiment, develop attitudes, skills, and values plus learn to share with one another. These relationships become prominent during middle childhood and adolescence and it contributes to mitigate negative impacts and amplify self-esteem" (Boyden et al., 2005:8).

At the same time, education is one of the key factors which helps children to cope with traumatic situations (Ajdukovic and Ajdukovic, 1998; Machel, 1996; Wessells and Jonah, 2006; Cilliers, 2006). Researchers say that education of children can be hampered due to war in several ways. For instance, schools may be damaged or destroyed by the conflict; teachers may have been killed, or may have fled, or have been forced into joining the fighting; children and their families may have been forced to flee their homes and may live in displacement camps where there are no schools or education opportunities (Sommers, 2002). Therefore, one of the main responsibilities and a challenge for a rehabilitation programme is to re-direct the affected children back to 
education (Machel, 1996; Wessells and Jonah, 2006). Because, even though children's trauma can impact their ability to learn (Ajdukovic, 1998) researchers claim that their mental rehabilitation can be sped up by providing educational opportunities.

For instance, Analyti (2001) shows that establishing social stability and setting up educational opportunities are some of the best ways to rehabilitate war-affected children. Education opportunities specifically can be used as effective mechanisms in order to re-integrate ex-child soldiers into mainstream society. For instance, Machel (1996) points out that one of the best ways to reintegrate child soldiers back to the society is to provide them with educational opportunities. According to him, this will increase their confidence and competencies which will help earn an income and restrain them from going back to war. According to Sommers (2003), education is also helpful to attain a 'sense of normalcy' for war-affected children, especially for child soldiers as they are compelled to face social stigma, which can marginalise them from the rest of the society. Further, researchers state that education can be used as a platform to give hope for the future among war-affected children. For instance, Nicolai and Triplehorn (2003) state that encouraging children to attend school regularly, do home work, adhere to classroom rules and regulations and sit examinations will enhance their confidence regarding their abilities, and may lead them to build-up a sense of purpose in their lives.

Apart from these, religious practices and traditional beliefs are also considered as effective coping strategies at times of stress (Antonovesky, 1979; Moskovitz, 1983; Clifford, 1997; Rinpoche, 1998; Somasundaram, 2007). Usage of traditional and religious beliefs for healing has been an accepted practice since ancient times in most cultures. Several studies reveal how religious beliefs and traditional practices have been used to heal and rehabilitate traumatized people. For example, African countries frequently use traditional healing methods and religious beliefs to restore their war-affected communities. Green and Honwana (1999) illustrate in their study of rehabilitating war-affected children in Mozambique and Angola that elders in the community had initiated the restoration and rehabilitation process through indigenous practices long before a structured programme was implemented by the experts. They have used the concepts of 'purification' and 'cleansing' to rehabilitate these child victims through traditional beliefs. These concepts are used symbolically to heal past memories inflicted by conflicts. For child soldiers and others affected by war, symbolic rituals were conducted in an attempt to help them recover from their traumatic past. Both family members and community leaders take part in these ceremonies. These rituals are performed to dispel any painful memories and bring healing, and make them a part of normal society. It is also done to relieve them of their sins and guilt. In performing these rituals the children are considered purified and they are given the assurance that they are no more unclean.

However, there is no particular reconciliation process in this practice but only a ritual which accepts the person back into society as a normal being. Researchers who conducted studies on 'application of traditional methodologies in rehabilitating war-affected children' point out that a gender disparity is also visible in these methods. Especially, when they are being practiced in third world countries where male dominance and gender stereotyping is strongly inbuilt (Tol et al., 2013).

Even though there are some weaknesses observed in practicing social contextual elements, researchers argue that rehabilitation programmes can benefit in using these elements in a few ways. Firstly, it allows a larger population to be served within the rehabilitation process. Citing de Jong's (2002) idea, Tol et al. (2013) and Somasundaram (2007) state that the social context approach facilitates coverage of a larger group of people, alongside a wider scope to create mental health awareness among the war-affected population. Secondly, it is believed that they can be accessed easily and at a lower cost. Tol et al. (2013) state that social context methods are more cost-effective in a setting where the mental health is not much developed; especially given that third world countries, where war is more prevalent, have a huge shortage of professionals in the field of psychiatry. For example, in Sri Lanka, there are only 90 psychiatrists in the whole country to serve a population of twenty million people (Directory of Mental Health and Psycho-social Services, 2013) ${ }^{1}$. This unfortunate situation is further exacerbated by the fact that even these psychiatrics are concentrated in urban areas rather than war-affected areas.

Due to the destructive nature of war the entire social fabric gets altered or destroyed. Somasundaram (2007) states that war do not only affect individuals but their entire families, community and society. Therefore, researchers are of the view that psycho-social rehabilitation programmes have a great responsibility to understand the stimulation of social context on victimised groups and how its alterations after war have impacted the children and the communities. It is not an easy task to restore a social context to its original state but making an effort to re-establish at least a few components of the social context can make a significant 
difference. For instance, Somasundaram (2007) states that before working directly with war-affected children, it is important to start with strengthening and rebuilding the family and village structures. He also states that rather than treating children individually, it will be more effective to rehabilitate them within a holistic framework.

\section{Economic dimension}

Psycho-social support involves a range of care and support interventions which are aimed at addressing children's issues and needs in a holistic manner and place psycho-social interventions inside wider developmental contexts, including economic sustenance. Youth in armed-conflict have often been involved both as victims as well as perpetrators of violence, responding to war and its effects in different ways. Not all individuals directly affected by conflict will develop long term stress-related symptoms. However, those who do may be greatly and possibly even permanently affected, which limits their ability to find and hold a job. In turn, productive employment may contribute to the recovery of affected individuals and reduce their likelihood of being drawn into future violence, thereby contributing to stability and peace building. Post-conflict development policy must address not only the reconstruction of physical capital, but also the reconstruction of psychological and social capacities of those who have lived through violent conflict.

Many factors exacerbating psycho-social distress, including economic deprivation, the rupture of social networks and negation of sense of belonging due to displacement are mitigated when war-affected individuals are integrated into society through employment (Hamilton et al., 1997; Evans and Repper, 2000). However, research in conflict specific contexts finds that distress, depression and PTSD reduce the likelihood of working ${ }^{2}$. Hence, the need for well-directed intervention is vital to assist youth whose psycho-social health has been affected by conflicts, to prevent their further marginalisation and exclusion.

Employment plays a vital role in promoting psychological wellbeing: the economic autonomy which it provides is central to defining social status. Especially for young males, their social recognition as young male adults may entail the ability to establish and support a family (Bannon and Correia, 2006). In its absence, youth may remain marginalised from economic, social, cultural and institutional systems. Therefore, more attention needs to be paid to the effects of employment on their identity and psychological well-being, on both men and women.

\section{THE EMPIRICAL FOUNDATION FOR A PSYCHO-SOCIAL REHABILITATION PROGRAMME}

Recent developments in psycho-social rehabilitation programmes and impact assessments are anchored in empirical studies conducted over the last several decades by many researchers from a variety of disciplines. To validate the elements that are essential for a psycho-social rehabilitation programme, the author has examined a few researches on psycho-social rehabilitation programmes done in different war contexts and attempted to derive essential programmatic components needed for a successful programme.

\section{Creating Life Options Through Skills Training and Employment Generation in Sierra Leone}

From 1991 to 2002, Sierra Leone endured a brutal civil war which left approximately 50,000 people dead, 20,000 brutally mutilated and three quarters of the country's population displaced. Sierra Leone's civil war devastated its economy, infrastructure and social services, as well as its people, leading to human rights abuses, including mass mutilations and pervasive use of children in armed conflict.

A few key investigations have been carried out on psycho-social rehabilitation of former child soldiers in Sierra Leone, including the Programme of Creating Life Options through Skills Training and Employment Generation. Wessells and Jonah (2006) commenting about this programme, say that some people consider exsoldiers as hardened killers who have been abused and forced to do violence, and thus have become 'damaged goods' with little chance of reintegrating into communities or recovering. This skills training programme was funded by Christian Children's Fund (CCF) with several objectives, the first being to carry them through a reconciliation process to cultivate behaviours of peace, justice, mercy, forgiveness and restitution. The second was to restore children from poverty and destitution, fulfilling their basic needs and rights, so that children can be kept away from violence, directing them towards education and economic development.

Thirdly, the organisers of Skills Training and Employment Generation (STEG) identified that child soldiers had an 'identity crisis' due to trauma, deprivation, guilt and anxiety, and thus found it difficult to turn away from military identity to civilian identity. Since they lacked life skills and confidence needed to re-integrate and lead a normal meaningful life they felt stigmatised. At the same time, they identified that these former child soldiers suffered from a lack of positive civilian roles in 
their respective societies. Therefore, it is important to identify ways of empowerment to re-integrate them back to society to take up active and respected roles.

Fourthly, they showed that in most African societies, spirituality takes a central place in people's lives and therefore, their traditional religious beliefs hold an important place in resolving issues of conflict and violence. However, most of the researchers are of the view that these indigenous practices are not sufficient to bring about the expected results of rehabilitation and, therefore, the need arises to involve the intervention of experts as well.

In order to solve the above-mentioned issues of child soldiers and members of the respective communities, STEG programme was commenced in 15 communities in Sierra Leone. They followed certain steps before and even after implementing this programme in the respective communities. The first step was Christian Children's Foundation (CCF) team meeting children, community leaders, religious leaders, traditional healers and elders to discuss the objective of the programme and to plan the ways they intended to implement the programme. In the second step, the programme requested the elders of the community to get involved in identifying and prioritising the developmental needs of children. Third step was the training of local chiefs, elders, senior women, youth and another 30 opinion makers on how indigenous practices can be effectively used in rehabilitating war-affected children as well as a wider understanding and perspective of psycho-social rehabilitation.

The fourth step was selecting workers who would conduct the planned activities of the programme. They retained the trained workers, 60 percent of whom were former child soldiers with the other 40 percent being civilians. The fifth step was to prepare the selected workers to conduct both civic works projects and reconciliation activities.

First they conducted a two-day psycho-social workshop on reconciliation, imparting training on healing, stress reduction, spirituality and peace. They further trained on how to conduct civic works projects with the main concerns covered being health and nutrition, education and general infrastructure development. The next step was for the funding organisation to provide the necessary finances, materials, consultations and supervision while the community engaged in planning and implementation. They completed 53 civic projects, with the support of 2040 ex-combatants and 1380 civilians. Each of them were paid $\$ 27$ for full time work of 20 days per month. According to the findings of
Wessells and Jonah (2006), it was too soon to comment on the impact of these programmes. The comments from the community members, however, made it evident that the rehabilitation programme had achieved commendable impact.

By analysing the features of this programme as a whole, it can be said that they have taken a holistic approach in rehabilitating the ex-combatants. They clearly had an understanding of the war context and what needed to be done to rehabilitate these children. For instance, as the first step they have collected baseline information on the children and their particular communities, in trying to identify their specific needs for psycho-social assistance. Next they envisioned the programme's objectives based on this information, their observations and careful analysis. Therefore, this programme reveals that 'assessing' the situation is an important feature in a rehabilitation process, where data can be obtained to derive the objectives and purposes of the programme. Further, STEG programme had planned their programme well, covering the three main dimensions of psychosocial rehabilitation even though they did focus more on the economic dimension of rehabilitation compared to social and psychological dimensions.

Since this programme was fully funded by $\mathrm{CCF}$, there were sufficient financial resources to run it consistently. They were also able to obtain skilled human resources through this funding to support the programme. In addition, they maintained good networking with the community and their stakeholders, since the programme involved them in identifying and prioritising the developmental needs of children. Capacitating the community leaders, receiving their support in caring for children, involving them in programme activities, were some of the key networking initiatives they took to ensure the sustainability of the programme. They used community-based strategies of skills development, employment, cooperation, dialogue and psychosocial support. Organising civic projects, building community capacities and strengthening resilience were some of the key strategies they employed to engage with the community in social work. They selected a rehabilitation strategy which was purely based on the traditional practices and beliefs. Their rehabilitation techniques were also derived out of these cultural and religious beliefs. Therefore, having a clear rehabilitation approach, methodology and techniques is important to a programme. According to the information available on the STEG programme, it is apparent that they concentrated more on activity monitoring and supervision rather than individual child monitoring. However, both activity and child level monitoring are needed for a successful 
psycho-social programme, as the ultimate transformation of a child's life is of utmost importance to society. They have conducted impact studies on the programme's activities and a project evaluation which has captured some changes.

\section{Community-Based Children's Play Activity Programme in Sri Lanka}

Tribe (2004) has done an evaluation regarding the 'Community-Based Children's Play Activity programme' (CBCPA programme) from which several lessons can be drawn to be incorporated into this research. Play activity programme was one of a series of interlocking programmes run by the Family Rehabilitation Centre (FRC), a Sri Lankan non-governmental organisation whose aim was to assist those children affected by armed conflict in all areas of Sri Lanka, irrespective of ethnicity, religion and political ideology. This programme started in 1992 and according to Tribe (2004), CBCPA programme continued up to the time the research was completed. It was a programme which involved multi-level interventions in working with children, their caretakers, health and education professionals and community leaders. This programme covers nine Internally Displaced People's (IDP) camps located in several war-affected areas in Sri Lanka. Tribe (2004) states that there were two broad objectives in this programme:

1. Identifying the psycho-social needs of children exposed to armed conflict and providing interventions to promote their healthy growth and development.

2. Enabling caretakers, parents, teachers and others interacting with children to identify the ones who are at high risk and give them confidence in themselves in working to assist needy children.

It is further explained how the activities were planned in the programme in order to achieve these two objectives. They are as follows:

1. Trying to provide a structured environment where care, feelings and concerns about their own situations and its effect on their children could be shared and ways of working with them is considered.

2. Developing an intervention programme with local experts and identifying children with 'trauma or stress related difficulties'.
3. Gathering knowledge about the needs of children for healthy psycho-social development.

4. Developing the participants' skills on practical therapeutic play activities, care or parental involvement and interaction, plus other relevant interventions.

5. Developing skills among the play leaders/ caretakers to conduct training programmes at a basic level using cascade/ waterfall methodology.

Their major target group were children who were selected across nine IDP camps. There is considerable evidence that displaced children are at significant risk of developing psychological disturbances as they are subjected to a number of risk factors (Fazel et al., 2002). Therefore, if rehabilitation programmes address the psycho-social needs of children living in IDP camps, then these children will not be alienated. Referring to the above section, it can be concluded that the CBCPA programme has clearly identified their target group and their rehabilitation need, which have helped them to focus the programme as well as achieve its objectives. Therefore, target group identification can be considered as a necessity in programme planning.

The interventions were based on the FRC philosophy, which holds that well-being is multifaceted and that psychological health is embedded into the matrix of well-being. These may include social, community, spiritual and socio-political issues. The coping strategies used by some of the survivors were incorporated as an important component of the FRC programme. The FRC team developed over time a multilevel play activity programme based on the research literature, community resources and skills, cultural and psychological knowledge plus training. They had different interventions planned within the programme at different levels. One level of the intervention involved organising a range of structured child-centred 'play activities', which includes drawing, storytelling, free play, art, dancing and traditional games. Another level of intervention involved meeting regularly with the group of carers and adult members of the community and providing information and resources about child development, possible reactions to being exposed to civil war, traumatic events, family process, violence and loss. The third level involved regular meetings conducted for the health and education workers who have joined the programme. The aim of this activity was to improve their competence in working and dealing with the children 
as well as to strengthen their confidence for successful job performance. The play leaders undertake regular training sessions at the FRC headquarters in Colombo. The first training programme was run by workers from the Children's Rehabilitation Centre (CRC) located in the Philippines. The senior counsellors and programme director of the FRC provide ongoing supervision and support for the play leaders.

Another unique feature of the programme was its implementation strategy. They recognised the important role indigenous healers and resource persons play within their communities and invited them to collaborate and participate actively in all FRC programmes. They were making an extremely valuable contribution in helping individuals; these helpers are well-placed to assist in the re-establishment of communities and networks of helping and healing as displaced people start to return and rebuild their lives and communities. Therefore, even if financial assistance ceases, people in the community have acquired an understanding, knowledge and capacity plus strength to continue the activities without external support. With this being so, a question can be raised here as to why many people refer to cultural or indigenous healing methods as important techniques in rehabilitating war-affected children. As mentioned earlier, one reason could be the-lack of necessary human and material resources in war affected countries. For instance, as mentioned earlier there are only 90 psychiatrists in Sri Lanka (Directory of Mental Health and Psychosocial Services, 2013). Therefore, it is impossible for all those who are under mental stress due to war to obtain treatment from professionals and thus the alternative would be to facilitate at least the indigenous healing methods widely available.

According to the research findings of Tribe (2004), a systematic monitoring of the programme was undertaken and sustainability was constantly reviewed. The FRC team worked alongside adults of their programme to try and assist them in re-activating and regaining some of their emotional equilibrium and coping skills, thereby increasing their psychological resilience and regaining their ability to care for and support the children. The programme uses a collaborative design to build in opportunities for participants to share information, strategies and narratives.

Accordingly, CBCPA programme validates all four components of the analytical framework; Assessment, Planning, Implementation and Monitoring at various levels. Under Assessment section, situation and needs analysis can be endorsed through their assessments of the war situation, coping mechanism of children, their rehabilitation needs and indigenous healing methods. Since monitoring was done on a systematic basis, one can assume they kept records, including the baseline data, which is the usual practice in periodic monitoring. In the Planning section they had identified very specific objectives and clear guidance on activities required to achieve those objectives with an adequate resource base. Financial resources were mainly provided by the FRC organisation but they intentionally built on their human resources base providing local and international training for staff and capacitating the community leaders and elders to respond to the psycho-social needs of displaced children. Through these external capacity building initiatives they developed a strong network to support their interventions. The CBCPA implemented its programme by taking on a traditional approach, considering the indigenous healing methods for psycho-social rehabilitation and their expertise on play therapy. Then the methodologies, techniques and different interventions were constructed in alignment with these approaches. Therefore, components of the implementation system could be verified through these initiatives. Research literature gives an indication on the systematic monitoring and constant review process which was ongoing throughout the programme. But it does not clearly identify the child and activity monitoring separately. However, they have worked with adults of the IDP camps and reviewed their progress to ensure that they are well equipped to psychologically care for their children. Therefore, the author has derived from this the importance of monitoring the activities of the rehabilitation programme and progress made on the lives of children through those activities.

\section{DISCUSSION}

One of the main purposes of this paper is to identify the basic elements in a psycho-social rehabilitation programme, by using global level discourse regarding the effects of war on children and how they can be rehabilitated. Accordingly, the author identified a few key elements, which need to be included in a psychosocial rehabilitation. At the same time, the author has identified some of the important components that produce a meaningful impact of a psycho-social rehabilitation programme. The following sections elaborate in detail each component and their sub elements.

\section{Programme assessment components}

\section{Assessment}

To ensure the success of any programme, it is essential to assess the ground realities before commencing project 
work. At first, there must be a need analysis and problem identification. It is important do a need analysis in order to find the intensity of the need to rehabilitate children with the current situation. In a war context, studying the external environment is extremely important, especially when the programme is physically located in the area. An analysis to assess the strength, opportunities, weakness and risk will help a program to know the realities of external environment including their friends, rivals, and any viable threats which can be deciding factors affecting the impact of the programme.

Secondly, there is a need for baseline studies. Ideally a baseline survey needs to be developed and created when social data is being collected at the beginning of a project. The purpose of a baseline study is to provide an information base against which to monitor and assess an activity's progress and effectiveness during implementation and after the activity is completed. In these instances baseline values can refer to pre-condition of the children before they entered in to rehabilitation programme or condition of the social context or any particular intervention before commencement of the programme. Many research methods can be used to obtain baseline data, such as surveys, interviews, or focus group discussions, or even visual items, including photographs, maps and diagrams. It is often necessary to be creative and innovative about the data sources used since this is regarding children and psychological conditions.

\section{Planning}

When planning a meaningful programme three factors must be taken into consideration. The first is defining the purpose and objectives. Purpose and objectives will guide the programme to be focused on the area and scope of work. However, in a rehabilitation programme, purpose and objectives should also depend on the analysis done on the external and internal environment, especially focusing on the strength and opportunities. There can be occasions where the purposes and objectives can be influenced by strong factors like funding agencies, staff capacity and even social and political will. Some psycho-social rehabilitation programmes tend to focus on negative psychological effects of war and define their purpose while others develop their aspirations considering coping strategies of children. Anyhow, it is important to have clear and measureable objectives and indicators that are established at the initial stages of a psycho-social support intervention.

Second, select a proper and primary focus area target group. Selecting a geographical base focus area and a target group who is directly and positively affected by the intervention is essential to any project. In psychosocial intervention, selection of target is heavily important because they will directly influence the impact of the program. For instance, Agger et al. (1995) say that choosing the children who really need psycho-social care should be the first step that should be taken by the psycho-social rehabilitation. Therefore, children who are evidently psychologically affected and are under the influence of trauma, need to come into the target group. Having suitable selection criteria and capable people to execute these selections will be significant for a program. Primary focus areas are selected locations from the main impact area, where the effects of war have been heavily felt; they also should contain larger population of children who are vulnerable and in need of rehabilitation. These areas can be selected based on geographical boundaries depending on accessibility.

Third, finding proper funding mechanism. One of the most important elements in starting an organisation or programme is to secure funding needed to run the operations. In similar manner to ensure the continuity of a psycho-social programme and its completion having adequate funding is a necessity. If funding is inadequate the programme should always looks for alternative ways to fund a programme including community, without discontinuing and without bring in negative impacts (Wessells and Jonah, 2006). Therefore, planning for funding is essential, for it will bring down the risk of discontinuity of the programme which will negatively influence the impact. The success of an organisation is heavily reliant on the talent and strength of its employees. Therefore, having competent workers is significantly important in a psycho-social rehabilitation programme, especially because it is entirely a labour oriented process.

Fourth, build-up of networking and partnerships. Partners can be individuals, groups or organisations that share programme's vision in achieving the objectives. Partnerships can support a programme to increase local ownership and capacity and will make the rehabilitation process more sustainable. Networking is a way of creating partnerships; each programme can determine which and what forms of collaboration is appropriate to achieve rehabilitation objectives.

\section{Implementation}

Implementation stage is where programme has to operationalise its activities. The programme has to decide on the approach, methodologies and techniques that they have to adopt in order to implement its interventions. As mentioned in the first part of the article, psychosocial rehabilitation has different dimensions. Therefore, 
intervention has to be designed considering one or several of these dimensions depending on the need, objective and capacity of the implementers.

Psycho-social rehabilitation approaches mainly leads to two broad intervention areas: the first aimed at improving the individuals' competencies, while second aimed at introducing environmental changes to improve individuals' quality of life. In the early years, much more emphasis has been put on the development of individual-based approaches, leading to a narrow view of psycho-social rehabilitation as a set of more or less defined techniques targeted at addressing psychological concerns. After the Second World War, more attention was given towards environmental changes. This included the social, cultural and economic factors relating to the individuals. Anyhow, with the advancement of these approaches a need arose to strike a balance between them to increase the impact of psycho-social rehabilitation. Yet, some tend to take a more individualistic-based approach limited to bio-medical and advance counseling therapies, while others use social contextual factors like education, family relationships, religion, traditional and cultural practices in the process of rehabilitation.

\section{Monitoring}

Monitoring is examining progress against the targets of a programme; it is a continuous assessment that aims at providing early detailed information on the progress or delay of the ongoing assessed activities. Its purpose is to determine if the impact, deliveries and schedules planned have been reached so that action can be taken to correct the deficiencies as quickly as possible. Monitoring can be somewhat difficult in psycho-social programmes, because it needs to differentiate activity monitoring and child monitoring which can even need the support of a mental health expert in order to assess progress of rehabilitation. However, for monitoring results to be authentic, it needs to be done over a long period of time because most psycho-social changes are applicable once children are re-integrated to the society. However, monitoring and evaluation should be inbuilt in a programme and should have a mechanism to be carried out in order to improve the programme's effect.

\section{Programmatic impact}

Based on the field observations, assessments and the literature reviews, a new impacts framework for a psycho-social programme was proposed with preferred menu of indicators that can be used to evaluate and analyse the programmatic impact. The impact framework demonstrates the key components which contribute to the total impact of the programme. The author has considered few areas which can serve as key impact components of a rehabilitation programme. At the same time in this research, the author considers 'impact' as all the positive factors that war-affected children are given by the programmes and how it influences children's wellbeing. In this way the programme's influence for positive direction of children's lives will be identified as 'impact' in this study.

\section{Fulfillment of basic needs of children}

Many researchers have highlighted the importance of fulfilling the basic needs of victimised children before starting on psycho-social activities. Critiques say that most rehabilitation programmes concentrate on fulfilling psychological and social needs of children, whereas basic needs such as food, shelter, health and sanitation, and water are given less attention (Williamson, 1990). In another instance, Green and Honwana (1999) and Honwana (2008), refer to Mozambique and Angola child soldier rehabilitation, explaining that greater part of rehabilitation is achieved when the basic material needs are met. Highlighting war in Sierra Leon, even when the war was over, many child soldiers were willing to engage in acts of violence to fulfill their basic requirements, like food, clothing and even education and income. For instance, Wessells (2008) says that if people are very poor, and if they suffer from hunger, people will have an aversion to peace in a society. Therefore, attending to these requirements was a good way to start rehabilitation.

\section{Efforts of 'empowerment'}

Need for empowerment of children victimised by war to rebuild their positive attitudes and behavior towards themselves, family and society will be a prime aspect of a psycho-social rehabilitation programme. According to theoretical discussions, there are two ways to empower these children, one is to expand the educational opportunities of children which can help them to regain their confidence, rebuild positive self image and even lead to economic opportunities (Machel, 1996; Sommers, 2002; Sommers, 2003; Nicolai and Triplehorn, 2003; Maurin, 2006).

The second way of empowerment is to direct them for peace building activities, encouraging them to take part in leadership activities. For instance, according to Moskovitz (1983), making children feel valued to the society and allowing them to take up social responsibilities is one coping mechanism to deal with stressful situations.

Accepting the above view, Helsing et al. (2006) confirm that engaging children for peace-creating 
activities clearly makes positive impact on both children and society. Therefore, they suggest that broader discussion is needed on how to empower children and how to motivate them towards these initiatives.

\section{Re-building the social context}

This paper explaines how social context influenced the healing of people who have undergone traumatic experiences. It was found that family, peer groups, education institutions and religion have a unique ability to heal stressed people (Antonovesky, 1979; Moskovitz, 1983; Loughry and Eyber, 2003; Garbarino and Kostelny, 1996; Boyden et al., 2005; Clifford, 1997, Somasundaram, 2007).

However, during a war, the above mentioned social context or the coping strategies might be very limited or even unavailable since the entire social fabric gets altered or destroyed due to war. Somasundaram (2007) states that the entire social system can be destroyed due to conflict. Therefore, the psycho-social rehabilitation programmes have a great responsibility of understanding how social context have been altered due to war and its impact on children. If these programmes are to work for the well-being of children, they should pay attention to re-create what was damaged.

\section{Psychological improvement of children}

Psychological improvement through direct psychotherapy or psychiatric treatment is a key expected outcome of a psycho-social rehabilitation programme. It consists of a series of techniques for treating mental health, emotional and some psychiatric disorders. It helps the children understand their life and how to deal with positive or anxious thoughts, accepting their strong and weak points. When they get to identify their feelings and ways of thinking, they become better at coping with difficult situations. Such psychological empowerment will help them take control of their own care and protection, while building trust, understanding and developing skills to improve relationships. Therefore, rehabilitation impact will be holistic with psychological improvement of children along with the other components mentioned above.

\section{CONCLUSION}

This paper has focused on two issues. One is to examine how and when the concept of psycho-social emerged. It was discussed that after 1970 this concept was developed following Second World War.

The second issue explored was identifying basic components of a psycho-social rehabilitation programme. Accordingly, two sets of components were identified; one is basic components of identifying a structure of a programme while other is to identifying the impact of a psycho-social rehabilitation programme. Before constructing analysis frameworks, the need and advancement of psycho-social development in war contexts was explored to understand the current status of psycho-social discourse. It was shown that psycho-social development can be seen as a multi-dimensional concept. Psychological, social and economic are the broader dimensions. The treatment of mental and emotional disorders through the use of psychological techniques are designed with the goal of relieving symptoms, changes in behaviour leading to improved social and vocational functioning, and personality growth. The empirical foundations for these frameworks were built through researches done on African and Sri Lankan rehabilitation programmes and the literature review. In this paper the author has described the programmes used to validate the assessment components. She has reviewed the purpose and objectives of the programmes and the process of rehabilitation each programme followed, while commenting on the impact they have achieved in each area. Theoretical perspective have been considered to justify some of their programme interventions. The first sets of components help to assess rehabilitation programmes consist of four main phases; Assessment, Planning, Implementation and Monitoring. Different sub components have been listed under each phase, but the author has applied no strict principal that each sub component should be followed in each phase; Due to many practical reasons programmes need to be flexible to adapt to the contextual changes when going through this cycle. The second set of components relates to the combination areas of impact of rehabilitation programmes such as empowerment through education and economic development, fulfillment of basic needs, contribution to enhance social context and the direct psychological advancement of children.

\section{END NOTES}

1. Www.econsortium.infor/psy/index [Accessed: $12^{\text {th }}$ March 2014]

2. According to the American Psychiatric Association, Post-Traumatic Stress Disorder (PTSD) "is a psychiatric disorder that can occur in people who have experienced or witnessed life-threatening events such as natural disasters, serious accidents, terrorist incidents, war or violent personal assaults like rape. People who suffer from PTSD often relive the experience through flashbacks or nightmares, have difficulty sleeping and feel detached or estranged. (See http://www.healthyminds.org/ multimedia/ptsd.pdf) 


\section{REFERENCES}

Agger, I., Jensen, S. B. and Jacobs, M. (1995) Under war conditions: what defines a psycho-social project? In I. Agger, S. Vuk, and J. Mimica (eds.) Theory and practice of psychosocial projects under war conditions in Bosnia-Herzegovina and Croatia, Zagreb: European Community Humanitarian Office And European Community Task Force.

Analyti, A. (2012) War-affected children: psychological trauma and intervention crisis [Online] Available from: http://crisis. med.uoa.gr/elibrary/1.pdf [Accessed: $16^{\text {th }}$ February 2014]

Antonovsky, A. (1979) Health, stress and coping: new perspectives on mental and physical well-being, San Francisco: Jossey-Bass.

Betancourt, T. S. (2005) Stressors, supports and the social ecology of displacement: psycho-social dimensions of an emergency education program for Chechen adolescents displaced in Ingushetia, Russia, Culture, Medicine and Psychiatry, 29 (3), pp:309-340.

DOI: https://doi.org/10.1007/s11013-005-9170-9

Boyden, J. and Mann, G. (2005) Children's risk, resilience, and coping in extreme situations. In Ungar, M. (ed) Handbook for working with children and youth: ways to resilience across cultures and contexts Lomdom, New Delhi: Sage Publications. DOI: https://doi.org/10.4135/9781412976312.n1

Cilliers, J. (2006) Transforming post accord education system: local reflection from Bosnia-Herzegovina. In McEvoy-Levy, S. (ed) Trouble makers or peace makers? Youth and post accord peace building, North Dame, Indiana: University of North Dame Press, pp:173-194.

Clifford, T. (1990) Tibetan Buddhist medicine and psychiatry: the Diamond Healing, Weiser Books.

Duncan, J. and Arntson, L. (2004) Children in crisis: good practices in evaluating psycho-social programming, Save the Children Federation Inc.

Earle, L. and Earle, T. (1999) Systems model of social change based on social needs and social issues, South Pacific Journal of Psychology, 11 (2), pp: 1-5.

DOI: https://doi.org/10.1017/S0257543400000572

Fazel. M. and Stein, A. (2009) The mental health of refugee children [Online] Available from: https://www.ncbi.nlm.nih. gov/pubmed/12390902 [Accessed: $13^{\text {th }}$ August 2014]

Figley, C. (ed.) (1978) Stress disorders among Vietnam veterans: theory, research and treatment, Brunner- Routledge.

Freud, A. and Burlingham, D. (1943) War and Children, New York

Garbarino, J. and Kostelny, K. (1996) What do we need to know to understand children in community violence? In. Apfel,
R. J and Simon, B. (eds) Minefields in their hearts: the mental health of children in war and communal violence, New Haven, London: Yale University Press, pp.33-51.

Green, E., C. and Honwana, A. (1999) Indigenous healing of war-affected children in Africa, Indigenous Knowledge (IK) Notes; No. 10. [Online] Available from: https://openknowledge. worldbank.org/handle/10986/10828 [Accessed: 15 ${ }^{\text {th }}$ March 2014] Washington, DC, The World Bank.

Helsing, J., Kirlic, W. N., McMaster, N. and Sonnenschein, N. (2006) Young people's Activism and the transition to peace: Bosnia, Northern Ireland and Israel, In McEvoy-Levy, S. (ed.) Trouble makers or peace makers? Youth and post accord peace building, North Dame, Indiana: University of North Dame Press, pp:195-216.

Honwana, A. (2008) Reintegration of youth into society in the aftermath of war. [Online] Available from: http://www. un.org/esa/socdev/unyin/documents/namibia_honwana.pdf [Accessed: 18 ${ }^{\text {th }}$ April 2013]

Loughry, M. \& Eyber, C. (2003) Psycho-social concepts in humanitarian work with children: a review of the concepts and related literature, Washington: National Academies Press.

Machel, G. (1996) Promotion and protection of the rights of children: impacts of the armed conflict on children. United Nations, UNICEF.

Maurin, J. (2006) Education initiatives for war affected youth: an examination of programmes in Sierra Leone and Liberia [Online] Available from: http://www.stanford.edu/dept/SUSE/ ICE/monographs/maurin.pdf [Accessed: $16^{\text {th }}$ May 2014]

McEvoy-Levy, S. (ed.) (2006) Troublemakers or peace makers?: youth and post-accord peace building, North Dame, Indiana: University of North Dame Press.

Moskovitz, S. (1983) Child survivors of the holocaust and their adult lives, New York: Schocken.

Nicolai, S. and Triplehorn, C. (2003) The role of education in protecting children in conflict, Network Paper: Humanitarian Practice Network (HPN), 42, pp: 1-36, London: Overseas Development institute.

Nylund, B. V., Legrand, J. C. and Holtsberg, P. (1999) The role of art in psycho-social care and protection for displace children [Online] Available from: http://escolapau.uab.cat/img/ programas/musica/the_role_of_art.pdf [Accessed: $12^{\text {th }}$ August 2010]

Pupavac, V. (2004) Psychological interventions and the demoralization of humanitarianism, Journal of Biosocial Science, 36, pp: 491-504, Cambridge: Cambridge University Press.

DOI: https://doi.org/10.1017/S0021932004006613

Richman, N. (1996) Principles of help for children involved in organized violence, Westport, CT: Save the Children. 
Schnurr, P. P., Friedman M. J. and Bernardy, N. C. (2002) Reserach on post traumatic stress disorder: epidemology, pathophysiology and assessment, Journal of Clinical Psychology, 58(8), pp: 877-889.

DOI: https://doi.org/10.1002/jclp.10064

Somasundaram, D. (2007) Collective trauma in Northern Sri Lanka: a qualitative psychological- ecological study [Online] Available from: https://ijmhs.biomedcentral.com/ articles/10.1186/1752-4458-1-5 [Accessed: 20 $0^{\text {th }}$ May 2015]

Sommers, M. (2003) Education in emergencies, Washington, DC: Creative Associates International.

Summerfield, D. (1996) The impact of war and atrocity on civilian populations: basic principles for NGO interventions and a critique of psycho-social trauma projects, [Online] Available from: https:/www.freedomfromtorture.org/sites/ default/files/documents/Summerfield-ImpactOfWar\%20.pdf [Accessed: 19 ${ }^{\text {th }}$ June 2014]

Tol, W. A., Jordans, M. J. D., Kohrt, B. A., Betancourt, T. S. and Komproe, I. H. (2013) Promoting mental health and psycho- social well being in children affected by political violence, In Fernando, C. and Ferrari, M. (eds.) Handbook of Resilience in Children of War, pp: 11-27, New York, Heidelberg, London: Springer.

DOI: https://doi.org/10.1007/978-1-4614-6375-7_2

Tribe, R. (2000) A critical review of the evolution of a multilevel community based children's play activity programme run by the Family Rehabilitation Centre throughout Sri Lanka, Journal of Refugee Studies, 17(01), pp: 114-134, Oxford: Oxford University Press.

DOI: https://doi.org/10.1093/jrs/17.1.114

Wessells, M. (2008) Child soldiers, peace education and post conflict reconciliation for peace [Online] Available from: http:// www.leaonline.com/doi/pdf. 2005 [Accessed: 12 ${ }^{\text {th }}$ June 2012]

Wessells, M. and Jonah, D. (2006) Recruitment and reintegration of former youth solders in Sierra Leone: challenges of reconciliation and post-accord peace building, In McEvoy-Levy, S. (ed.) Trouble makers or peace makers? Youth and post accord peace building, North Dame, Indiana: University of North Dame Press. 